\title{
L-Proline and D-Proline (Chiral Amino Acid Catalysts)
}

\section{Dhanaraju Mandalapu}

Medicinal and Process Chemistry Division, CSIR-Central Drug Research Institute, Lucknow 226031, India

dhanachems.18@gmail.com

Published online: 19.02 .2015

DOI: 10.1055/s-0034-1380270; Art ID: st-2014-v0509-v

\section{Introduction}

L-Proline and D-proline are often used as asymmetric organocatalysts for a variety of organic reactions, due to their conformational rigidity as compared to other amino acids. Where L-proline is a natural non-essential amino acid, D-proline is an unnatural amino acid, with one basic and one acidic center each. Owing to their wide applicability in asymmetric organocatalysis for the synthesis of enantiopure compounds in the last decade, this article is an update to spotlight No. 60 and $168 .{ }^{1}$
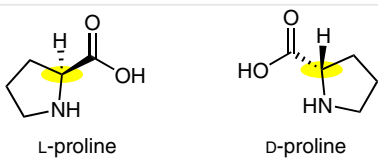

Figure 1 General structures of L-proline and D-proline
Dhanaraju Mandalapu was born in Tummagudem, Andhra Pradesh, India in 1988. He received his B.Sc. degree (2008) from Nagarjuna University, Guntur, Andhra Pradesh, India and his M.Sc. degree (2010) in organic chemistry from Andhra University, Visakhapatnam, Andhra Pradesh, India. At present, he works in medicinal chemistry at CSIR-Central Drug Research Institute, Lucknow, towards his Ph.D. under the guidance of Dr. V. L. Sharma. His current research project involves design and synthesis of biologically active compounds for the treatment of benign prostatic hyperplasia and contraception.

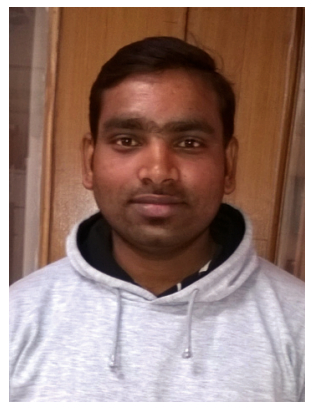

In the $21^{\text {st }}$ century, the use of small organic molecules as chiral organocatalysts has become a powerful strategy and an attractive field in organic chemistry. ${ }^{2}$ Among the catalysts developed, L/D-proline and its derivatives catalyzed a wide range of reactions. ${ }^{3} \mathrm{~L} / \mathrm{D}$-Proline collectively has the application as catalysts in asymmetric Mannich reactions for chiral $\beta$-aminocarbonyls, ${ }^{4}$ aldehyde aldol reaction for the synthesis of erythrose equivalents, ${ }^{5}$ domino Mannich-AzaMichael reactions, ${ }^{6}$ Morita-Bayllis-Hillman reactions, ${ }^{7}$ Heck cross-coupling reactions, ${ }^{8}$ multicomponent reations, ${ }^{9}$ in the synthesis of bioactive diketopiperazines, ${ }^{10}$ spirooxindazoles ${ }^{11}$ and also in phosphodiester bond linkages to recognize DNA and RNAs ${ }^{12}$ and in bifunctional catalysts, it acts as co-catalyst. ${ }^{13}$ In addition, the application in the preparation of a wide variety of chiral catalysts like chiral MOFs, ${ }^{14}$ Barbas-List aldol catalysts, ${ }^{15}$ bile acid catalysts ${ }^{16}$ and has excellent use in autocatalysis strategy, to form the initial enantiorich isomers, which further autocatalyze the reactions. ${ }^{17} \mathrm{~L} / \mathrm{D}$-proline also served as building blocks in construction of chiral 3D architectures. ${ }^{18}$

Table 1 Use of L-Proline and D-Proline (Chiral Amino Acid Catalysts)

(A) In a recent one-pot chiral synthesis, the Shi group ${ }^{19}$ used L/Dproline as Lewis base, in the presence of a chiral auxiliary group to synthesize substituted isoxazoline- $\mathrm{N}$-oxides highly chemo-/enantioselectively in good yields. With either L- or D-proline, the absolute stereochemistry of isoxazolidines was identical.

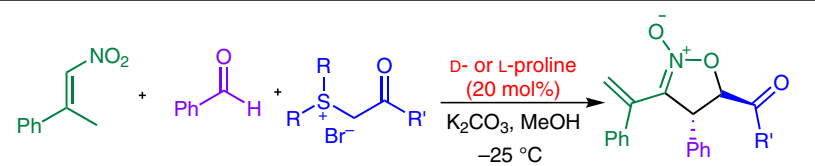

if catalyst D-proline: $90 \%$ yield, $86 \%$ ee L-proline: $87 \%$ yield, $87 \%$ ee

(B) If an additive is used, L/D-proline catalyze the cross-aldol reaction of ethyl benzoyl(diethoxymethyl)phosphinate and acetone for the synthesis of $\alpha$-hydroxy- $H$-phosphinate synthons in an organocatalyzed reaction. ${ }^{20}$ These are used in the synthesis of a variety of organic phosphorus compounds.

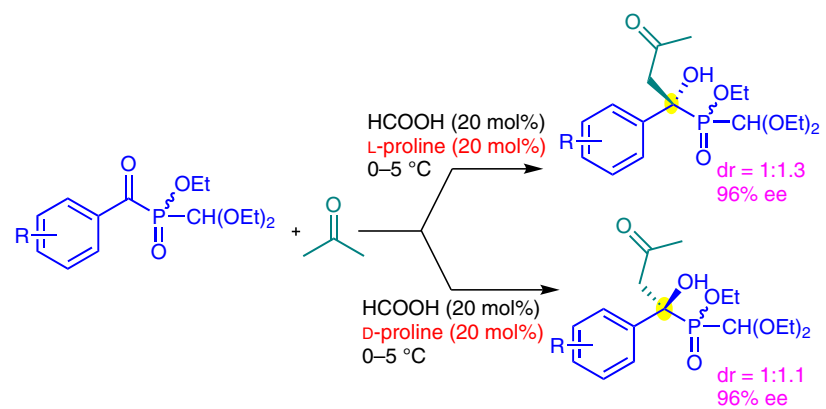


(C) In an enantioselective asymmetric hetero-Diels-Alder reaction of enones and aldehydes, the Zhao group ${ }^{21}$ used supramolecular bifunctional organocatalysts, which were synthesized by using L/Dproline and Cinchona alkaloids (quinidine thiourea), linked to each other through ionic hydrogen bonds for high stereoselectivity.

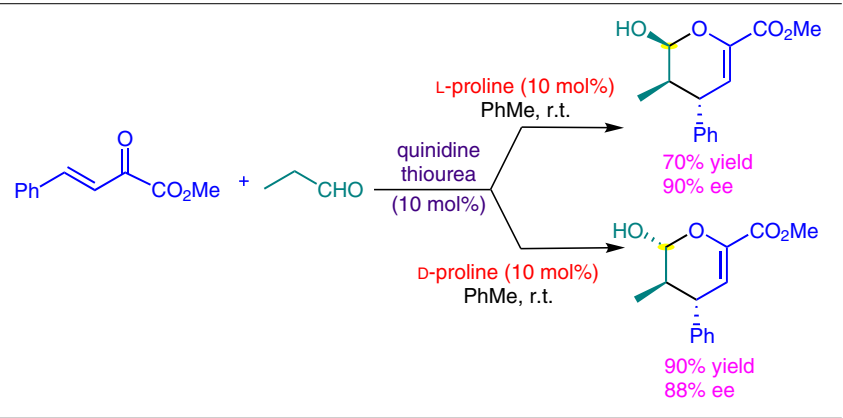

(D) L/D-Proline catalyze the asymmetric Morita-Baylis-Hillman (MBH) reaction in the presence of brucine- $N$-oxide as co-catalyst, through iminium intermediates. ${ }^{7}$ This dual catalytic system forms $\mathrm{MBH}$ products with opposite configuration with the respective L/Dproline in good enantioselectivities.
(E) Rawat et al. ${ }^{22}$ developed a novel L/D-proline catalyzed sequential $\boldsymbol{\alpha}$-amination-reductive cyclization of $o$-nitrohydroxy cinnamaldehydes for the construction of 3-substituted chiral tetrahydroquinolines (THQ) with good enantioselectivity, which were further applied in the total synthesis of bioactive (-)-sumanirole (96\% ee) and $(S)-903$ (92\% ee).

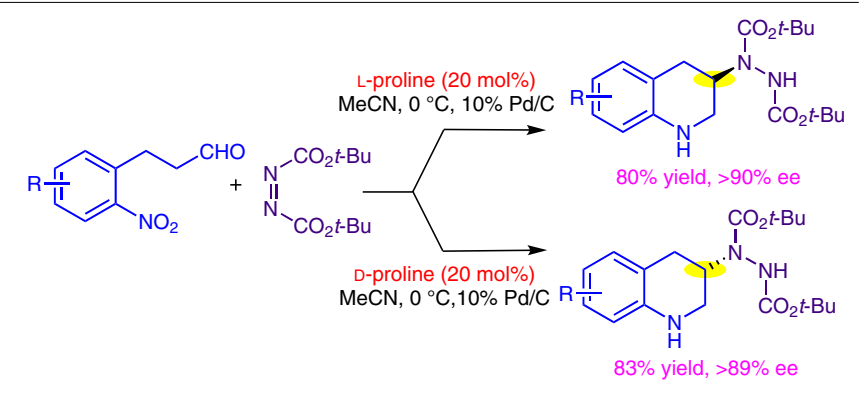

\section{References}

(1) (a) Paraskar, A. S. Synlett 2003, 582. (b) Lacoste, E. Synlett 2006, 1973.

(2) (a) Clarke, M. L.; Fuentes, J. A. Angew. Chem. Int. Ed. 2007, 46, 930. (b) Ibrahem, I.; Ma, G.; Afewerki, S.; Córdova, A. Angew. Chem. Int. Ed. 2013, 52, 878.

(3) (a) Trost, B. M.; Brindle, C. S. Chem. Soc. Rev. 2010, 39, 1600. (b) Albrecht, L.; Jiang, H.; Jørgensen, K. A. Chem. Eur. J. 2014, 20, 358.

(4) Yang, J. W.; Stadler, M.; List, B. Angew. Chem. Int. Ed. 2007, 46, 609.

(5) Carpenter, J.; Northrup, A. B.; Chung, d.; Wiener, J. J.; Kim, S. G.; MacMillan, D. W. Angew. Chem. Int. Ed. 2008, 47, 3568.

(6) Khaliel, S.; Nandakumar, M. V.; Krautscheid, H.; Schneider, C. Synlett 2008, 2705.

(7) Oh, K.; Li, J. Y.; Ryu, J. Org. Biomol. Chem. 2010, 8, 3015.

(8) Morel, A.; Silarska, E.; Trzeciak, A. M. Dalton Trans. 2013, 42, 1215.

(9) Morana, F.; Basso, A.; Riva, R.; Rocca, V.; Banfi, L. Chem. Eur. J. 2013, 19, 4563.

(10) Monbaliu, J. C.; Hansen, F. K.; Beagle, L. K.; Panzner, M. J.; Steel, P. J.; Todadze, E.; Stevens, C. V.; Katritzky, A. R. Chem. Eur. J. 2012, 18, 2632.

(11) Revathy, K.; Lalitha, A. RSC Adv. 2014, 4, 279.
(12) Bagmare, S.; D’Costa, M.; Kumar, V. A. Chem. Commun. 2009, 43, 6646.

(13) Ramachary, D. B.; Sakthidevi, R.; Shruthi, K. S. Chem. Eur. J. 2012, 18, 8008 .

(14) (a) Dhakshinamoorthy, A.; Asiri, A. M.; Garcia, H. Chem. Commun. 2014, 50, 12800. (b) Zhu, W.; He, C.; Wu, X.; Duan, C. Inorg. Chem. Comm. 2014, 39, 83. (c) Fresno, F.; Portela, R.; Suarez, S.; Coronado, J. M. J. Mater. Chem. A. 2014, 2, 2863.

(15) Pedrosa, R.; Andrés, J. M.; Manzano, R.; Román, D.; Téllez, S. Org. Biomol. Chem. 2011, 9, 935.

(16) Puleo, G. L.; Masib, M.; Iuliano, A. Tetrahedron: Asymmetry 2007, $18,1364$.

(17) Mauksch, M.; Tsogoeva, S. B.; Martynova, I. M.; Wei, S. Angew. Chem. Int. Ed. 2007, 46, 393.

(18) An, H. Y.; Wang, E. B.; Xiao, D. R.; Li, Y. G.; Su, Z. M.; Xu, L. Angew. Chem. Int. Ed. 2006, 45, 904.

(19) Zhong, C.; Gautam, L. N.; Petersen, J. L.; Akhmedov, N. G.; Shi, X. Chem. Eur. J. 2010, 16, 8605.

(20) Yao, Q.; Yuan, C. Chem. Eur. J. 2013, 19, 6080.

(21) Sinha, D.; Perera, S.; Zhao, J. C. Chem. Eur. J. 2013, 19, 6976.

(22) Rawat, V.; Kumar, B. S.; Sudalai, A. Org. Biomol. Chem. 2013, 11, 3608. 